\section{Analysis of Electronic Apex Locators in Human Teeth Diagnosed With Apical Periodontitis}

Norberto J. Broon ${ }^{1} \mathbb{D}$, Claudia Azucena Palafox-Sánchez² ${ }^{\mathbb{D}}$, Carlos Estrela $^{3}{ }^{-1}$, Diana Celeste Salazar-Camarena ${ }^{1} \mathbb{D}$, Mario Uribe ${ }^{1} \mathbb{D}$, Israel Ceja $^{4}$ D, Carlos S. Ramos ${ }^{5}$, Alvaro Cruz² ${ }^{\mathbb{D}}$

\begin{abstract}
Electronic apex locators (EAL) have been used to establish the working length $(\mathrm{WL})$ in root canal treatment. In teeth diagnosed with apical periodontitis, resorption of tooth apical structures can lead to difficulties to obtain an appropriate WL. The aim was to compare the capacity of three EAL's (Root ZX II, Raypex 6 and Endo-Eze Quill) to locate the tip of the K-file between 0 to $-0.5 \mathrm{~mm}$ from the apical foramen (AF) on teeth diagnosed with asymptomatic apical periodontitis (AAP). Electronic working length was performed on 60 roots with AAP. A K-file \#15 was inserted in the root canal until the apical foramen (AF) was located, and followed was re-adjusted to $-0.5 \mathrm{~mm}$ through observation in EAL display. The K-file was fixed to the tooth with composite and teeth were extracted. The 4 apical millimeters were worn out until the K-file could be seen and were prepared and measured its distance to AF in a scanning electron microscope. Appropriate WL was when the tip of the K-file was located between 0 to $-0.5 \mathrm{~mm}$ from AF. Results: Root ZX II showed significant difference $(p<0.01)$ with the other two EALs. Root ZX II presented the better performance than Raypex 6 or Endo-Eze Quill in teeth with AAP.
\end{abstract}

'University Center of Health Sciences (CUCS), Universidad de Guadalajara, México ${ }^{2}$ Research Institute of Biomedical Sciences, CUCS, México ${ }^{3}$ Department of Stomatologic Sciences, UFG - Universidade Federal de Goiás, Goiânia, G0, Brazil ${ }^{4}$ University Center of Exact Sciences and Engineering CUCEl, Universidad de Guadalajara, México ${ }^{5}$ Roseman University of Health Sciences, South Jordan, UT, USA

Correspondence: Alvaro Cruz, Avenida Francisco Javier Gamboa 230, 44150 Guadalajara, México. Tel: +52-33-3615-9804. e-mail: endoacruz@yahoo.com

\section{Introduction}

The therapeutic protocol to removal of vital or necrotic tissue, microorganisms and their products is challenging to the root canal treatment successful (1). The obtainment of an appropriate working length $(\mathrm{WL})$ is essential to predictive good endodontic therapy. The WL is the distance between a coronal reference point and an apical one (2), and it must be adequate so the damage to periapical tissues and interference with the healing process can be avoided (3).

The working length is established using radiographic and electronic methods (4). Radiographic determination of WL has been used for many years. However, it has difficulties and limitations. It does not allow observing the position of the apical foramen (AF) or identifying the cementum-dentin-canal zone (CDC), and the interpretation of the radiographic image is affected by superposition of anatomical structures (4). Custer (5) in 1918 suggested the electrical method for the first time under the electric conductivity principle. Suzuki (6) observed electrical activity in the periodontal ligament through constant values. Sunada (7) designed the first electronic apex locator (EAL) and called it "ohmmeter". This device had operated under the electric resistance principle.

Going forward, 2nd- (impedance), 3rd- (multifrequency) and 4th-generation (double frequency) EALs were developed (8). Root ZX and Raypex 6, work calculating the quotient of the impedances at two frequencies ( 0.4 and $8 \mathrm{kHz}$ ), measured simultaneous and continuous. Endo
Eze-Quill works use a spectrum of four frequencies (from 0.4 and $8 \mathrm{kHz}$ ). Every EAL calculates the AF by an own algorithm.

Apical periodontitis (AP) is a consequence of pulp necrosis and constitute on the inflammation of the apical periodontium, leading to morphological changes on the periapical area and radicular apex, identified as radiolucencies $(1,9)$. These structural modifications of the root and the AF must be considered during the endodontic treatment, as apical foramen (AF) localization and WL determination are more difficult on teeth with apical resorption (10).

Modern electronic apex locators can determine working length with accuracies of greater than $90 \%$. Root ZX II is a device with high precision and it is considered as the gold standard in electronic working length $(4,11)$. However, there is limited evidence on the clinical use of the mentioned EAL's to establish WL in teeth with AP $(10,12)$, especially with Raypex 6 and EndoEze-Quill. Therefore, this study compared Root ZX II, Raypex 6 and Endo-Eze Quill to locate the tip of the K-file between 0.0 to $-0.5 \mathrm{~mm}$ of the $A F$ in teeth with AP.

\section{Material and Methods}

Thirty patients of both genders, aged 20 to 60 years, who presented 36 teeth with diagnosis of pulpal necrosis (negative cold-test with Endo-Ice, Akron, $\mathrm{OH}, \mathrm{USA}$ ) and asymptomatic apical periodontitis (radiographically 
evaluated), indicated for tooth extraction were treated at the Endodontics Department of the Regional Military Specialty Hospital of Guadalajara, México. Maxillary and mandibular teeth (fifteen molars, nine premolars, and twelve incisors), with a total number of 60 root canals were included. In the case of a multiradicular tooth, every root showed radiographic periapical lesion. The cases of pregnancy, presence of internal resorption, root fractures, radiographically untreatable root canal path, massive coronal destruction or previous root canal treatment were excluded. This study was approval of the Ethics committee of the same Institution (CB/01/13). The patients were informed of the aims of this study, and written consent was obtained before their enrolment.

To calculate the size of the sample, the Power Analysis and Sample Size software (PASS 12, NCSS, Kaysville UT, USA) was used, obtaining a number of 15 samples per group, adding 30\% of them, for possible losses. Electronic measurements were carried out after being randomly allocated (www.random.org) to one of the three EAL: Root ZX II (J. Morita MFG Corp., Kyoto, Japan), Raypex 6 (VDW $\mathrm{GmbH}$, Munich, Germany) or Endo-Eze Quill (Ultradent Products Inc., South Jordan UT, USA).

All of the procedures were performed using sterile equipment. Local anesthesia was applied with 2\% lidocaine/ epinephrine (Zeyco FD, Zapopan, México) by regional and local techniques. With a water-cooled high-speed carbide bur \#2 to \#4 (Kerr, Glendora CA, USA) the previous restorations and decay were removed. After rubber dam isolation completed with Block-out resin (Ultradent Products Inc.), the tooth was disinfected with iodine, and conventional endodontic cavity access was prepared. Using a DG-16 explorer (Hu-Friedy; Chicago ILL, USA) the root canal was identified and the coronal or incisal surface of the tooth was worn off using a tapered diamond bur 17R5 (Kerr) in order to establish a perpendicular horizontal plane to the radicular axis. Two and a half percent sodium hypochlorite was used for irrigation (Clorox, México City, México). After exploration with a scouting \# 10 or \#15 K-file (VDW GmbH), cervical interferences from the root canals were removed with a Gates-Glidden \#3 (VDW GmbH). The excess of irrigant was sucked from the pulp chamber. With an active EAL and the external clip on the patient's buccal mucosa, a \#15 K-file was inserted to fit the anatomy of the previously identified root canal.

The K-file was attached to the file holder and the location of the AF was identified when the EAL display showed the location, following the manufacturer's instructions. The K-file was readjusted until it indicated $-0.5 \mathrm{~mm}$ short from the AF, Root ZX II on the green line, Raypex 6 on the first two yellow bars and Endo-Eze Quill on the green LED light. In most of the cases, the files were not fair in the apical portion. The K-file was maintained for at least $5 \mathrm{~s}$ so the reading could be stabilized, then fixed to the tooth with light-cured composite (Tetric $\mathrm{N}$-Collection, Ivoclar-Vivadent, Liechtenstein). The teeth were carefully extracted and maintained in 10\% buffered formaldehyde. Curettage of socket and sutures of gingiva were done. The conventional post-extraction indications were given to patients.

Under optical magnification 16X (OPMI 99, Carl Zeiss, Oberkochen, Germany), the buccal wall of the roots was worn out $4 \mathrm{~mm}$ apical to cervical with an XL Zekrya highspeed surgical bur (Dentsply, York PA, USA) cooling with water spray until the K-file could be seen. Five $\mathrm{mL}$ of EDTA (MD-Cleanser, Borgatta, México City, México) were used as final irrigation to remove dentinal debris from the apical wear. In the samples in which the K-file was visible outside the apical foramen, the roots were not worn.

The samples were dehydrated in 100\% ethanol, dried and covered by gold in a sputtering (Ernest F. Fullam, New York NY, USA) and observed in a high vacuum scanning electron microscope (MIRA 3 Tescan, Kohoutovice, Czech Republic). Apex amplified images (75X to 151X) were obtained, including AF and the tip of the file. The images were analyzed by three endodontists separately, blinded to each group. Prior to the evaluation, they received ten SEM images of worn apex roots where AF was visible, not related to the study sample, to calibrate. One week after, each endodontist established the beginning of the $A F_{\text {, }}$ following these instructions: the criterion used to locate the beginning of $\mathrm{AF}$ was the most cervical limit of the foramen; the most cervical limit of the foramen must be found and marked with a yellow line; when in doubt, a tentative limit on most cervical point of AF must be marked, and the three evaluators to reach a consensus must be discussed as "doubt".

All images were evaluated on a 24" LCD monitor (LMD2435MD Sony, Tokyo, Japan) in a dark room. Consensus by the three evaluators met as a group, was reached on samples marked as "doubt". Three weeks after the first evaluation, the endodontists again evaluated all images, under the same conditions. Agreement among and within evaluators was determined with Pearson's correlation coefficient (SPSS 13, Chicago IL, USA).

The most cervical limit of the foramen obtained by coincidence or consensus in each case was used to measure the distance from the tip of the K-file to the foramen. If the apical foramen was severely modified or eliminated, or the tip of the K-file was affected by the worn, the sample was excluded.

Using Adobe Photoshop 2015 software (Adobe Corp., San José, CA, USA), a calibrated operator in SEM, measured the distance from the tip of the file to the most cervical 
portion of $A F$, and the result was recorded on a data collection sheet. A precise criterion was assigned when the tip of the K-file was placed 0.0 to $-0.5 \mathrm{~mm}$ short from the most cervical portion of AF. It was longer if the $\mathrm{K}$-file was beyond ( $+0.1 \mathrm{~mm}$ or more) and shorter if it was $-0.51 \mathrm{~mm}$ or more from the AF. One-way ANOVA statistical test was used to evaluate the measures obtained with the three EALs, and Fisher's and Bonferroni's multiple comparisons posthoc tests were applied (statistical level significance $p<.05$ ).

\section{Results}

Out of the 60 samples, 9 teeth were excluded due to AF was eliminated or affected during the worn, and 4 due to the worn-looking tip of the K-file. A total of 47 roots were evaluated, 15 using Root ZX II, 17 using Raypex 6 and 15 using Endo-Eze Quill. Inter and intra agreement score was 0.96 and 0.98 . Table 1 presents the number, percentages of roots and minimum and maximum values of the position of the file obtained with each device.

The average distance (Fig. 1) from the tip of the K-file to the AF was $-0.11( \pm 0.58 \mathrm{~mm})$ for Root ZX II, $+0.37( \pm 0.62$ $\mathrm{mm})$ for Raypex 6, and $+0.33( \pm 0.78 \mathrm{~mm})$ for Endo-Eze Quill. ANOVA and Fisher's test showed statistical differences

$$
\text { 竞 }
$$

Raypex 6 and Endo-Eze Quill. SEM images of extracted roots with K-file from each EAL can be observed in Figure 2.

\section{Discussion}

The aim of this study was to compare the capacity of three EALs to determine the position of the $\mathrm{K}$ file tip between 0.0 to $-0.5 \mathrm{~mm}$ from the $\mathrm{AF}$ in teeth with $\mathrm{AP}$, because there is limited clinical evidence of its use in those teeth $(10,12)$. Regarding the results obtained, and with the criteria established, Root ZX showed an accuracy percentage of 53.3\%, Endo-Eze Quill of 46.6\%, while Raypex 6 of $37.5 \%$, which are values lower than those observed in other studies (10-17).

These differences were attributed to two factors. The first is the criteria to determine the beginning of the $A F$, which was established at its most cervical point. From an anatomical point of view, when the apical foramen is located in one of the lateral walls of the root apex (18) (Fig. $2 B)$, the foramen has its beginning at the most cervical limit, and from this point, the tip of the instrument reaches the periodontal ligament. In other studies (12-16) only "apical foramen" is mentioned, without considering this aspect. The second factor, the possibly led to these low results of the three EALs, also occurred due to the WL localization criteria. In this work, the margin of distance from the position of the file to the beginning of the AF was 0.0 to $-0.5 \mathrm{~mm}$, while other studies (12-16) established a range of \pm 0.5 and $+1 \mathrm{~mm}$ to the AF. In the present study, the value of $-0.5 \mathrm{~mm}$ was established as an accuracy $\mathrm{WL}$, because the average distance from the AF to the $\mathrm{CDC}$ zone is -0.52 $\mathrm{mm}$ (18), considering that the best healing results after the root canal treatment are obtained when the level is within the CDC zone (19). It is thought that by widening the range of measurement, results could increase their accuracy percentage, but the precision of the EAL would not be evaluated reliably.

The AP has a negative effect on the root canal treatment (19), because there is resorption at the periapical tissues, which destroys bone, cement, and dentin (1), which results in the formation of resorption lacunae (craters) in apical zone, foramen, and CDC zone deformation (9); furthermore, there is internal resorption in $74.7 \%$ of the roots with periapical disease (20). In teeth with AP, Piasecki et al. (10),

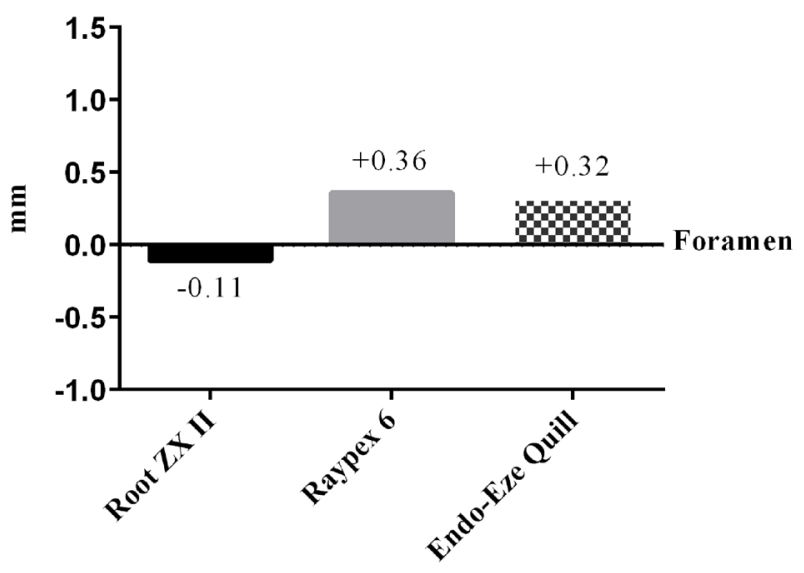

Figure 1. Distances means of the three EAL's. Negative values mean short of the AF. Positive values mean beyond of the AF

Table 1. Number and percentage of roots and the position of the file with respect to the beginning of the foramen. The minimum and maximum values in $\mathrm{mm}$ are in parentheses

\begin{tabular}{|c|c|c|c|c|}
\hline Device & Samples & Negative (shorter, >-0.5 mm) & Accuracy (0 to $-0.5 \mathrm{~mm}$ ) & Positive (beyond, >0 mm) \\
\hline Root ZX II & 15 & $3(20 \%)(-0.87$ to -1.27$)$ & $8(53.3 \%)(0.00$ to -0.43$)$ & $4(26.6 \%)(+0.12$ to +1.06$)$ \\
\hline Raypex 6 & 17 & $0(0 \%) 0(0 \%)$ & $6(37.5 \%)(0.00$ to -0.49$)$ & $11(64.7 \%)(+0.11$ to +1.77$)$ \\
\hline Endo-Eze Quill & 15 & $1(6.6 \%)(-1.11)$ & $7(46.6 \%)$ (0 to -0.34$)$ & $7(46.6 \%)(+0.10$ to +2.06$)$ \\
\hline
\end{tabular}


using the Root ZX, founded an accuracy of $83 \%$, while Saatchi et al. (12) also in teeth with AP, testing Dentaport ZX, Raypex 5 and i-Root, reported an accuracy of $93.8 \%$, $81.3 \%$, and $75.0 \%$, respectively, with a range of $+0.5 \mathrm{~mm}$. The accuracy found in these two studies $(10,12)$ in teeth with AP was greater than that observed in the present study, as reported at the beginning of this discussion section.

It is thought that WL is more precise in vital teeth than in teeth diagnosed with AP (10), maybe due to the electric resistance of the root canal in cases of AP diminishes due to resorption and the increase in the diameter of the CDC zone (20). Accuracy of EAL's can be variable according to the $A F$, and CDC zone diameter, as well as the brand and type of the used $\operatorname{EAL}(21,22)$. According to the results of this study, in teeth with AP, EAL's showed low precision to determine the WL.

In other conditions, EAL's have acceptable reliability to determine WL (10-17), including controlling the working length during the rotary instrumentation (23). Parente et al. (23) evaluated ex vivo the efficacy of Root ZX and Propex II to control the root canal WL during rotary instrumentation. The precision values of $0.0 \mathrm{~mm}$ and -1.0 were $100 \%$ and $0.0 \%$ for Root ZX, and 100\% and $66.7 \%$ for Propex, respectively, with a range of $\pm 0.5 \mathrm{~mm}$.

Wrbas et al. (14) evaluated in vivo Root ZX and Raypex 5 in vital teeth, with a range of $\pm 0.5 \mathrm{~mm}$. The results were statistically similar for both devices, with precision from $75 \%$ to $80 \%$ of the cases. Ravanshad et al. (17) evaluated the accuracy of the WL with Raypex 5 , being acceptable in $90 \%$ of the cases in the final obturation. In root canals with the presence of blood, Saatchi et al. (24) observed the accuracy of $86.2 \%$ for Root ZX and $83.3 \%$ for Raypex 5 , with a range of $+0.5 \mathrm{~mm}$ from $\mathrm{AF}$.

Stöber et al. (15) with a range of $+0.5 \mathrm{~mm}$ with Raypex 5 and MiniApex Locator obtained a percentage of accuracy of $75 \%$ and $77.8 \%$, respectively, while in these same samples when the range was $+1 \mathrm{~mm}$, precision was $100 \%$ for both devices. Similarly, Duran-Sindreu et al. (16) with Root ZX found $78.3 \%$ in the range of $+0.5 \mathrm{~mm}$; when the margin was extended to $+1 \mathrm{~mm}$, the precision was $100 \%$. Another factor pointed by Piasecki et al. (25), that can influence the accuracy of the EAL's, is when the distance from apical constriction to apical foramen is more than $0.5 \mathrm{~mm}$.

Tsesis et al. (22) in a meta-analysis study, found that gender, age, type of teeth, internal root canal humidity and device do not influence the precision; however, pulpal diagnosis and endodontic retreatment have a direct influence on the WL results. The WL short of the AF will keep the endodontic maneuvers within the root canal and will allow a biological WL with a better clinical prognosis $(3,19)$. In the present study, the measurement from the K-file tip to the AF was made differently from other studies $(10,12-$ $16)$, once that is less specific regarding which anatomical point is taken as a reference to measure the position of the $\mathrm{K}$-file. In radiographic evaluation (17), it was referring to the radicular apex. The AF is a variable three-dimensional anatomical structure therefore, it is critical to identify in which area of this anatomical space the measurement is obtained; as the WL on the same foramen can change if it is measured from its most apical or coronal border (11). In the literature, it was verified lack of studies that refer to previously identifying the starting point of $\mathrm{AF}$; therefore, in the measurement, its most cervical position was considered.

The degree and extension of apical resorption or the presence of accessory canals and comparing the same device in teeth with or without AP were not evaluated and may be considered a limitation of the study. Further studies regarding these clinical conditions are required.
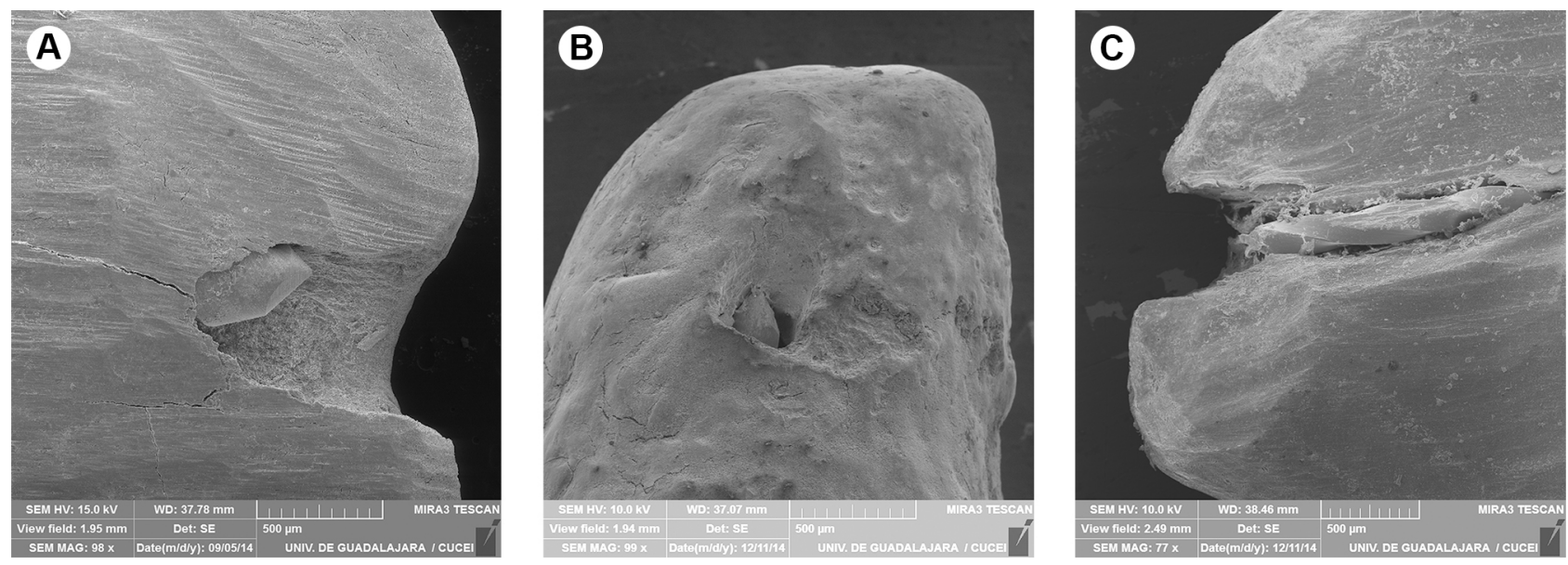

Figure 2. SEM images of the working length with the three devices. A: Root ZX II, precise in relation to the AF (SEM $15 \mathrm{kV}-98 \times$ ). B: Raypex 6: apical foramen is located on the distal wall of the root apex. Even the file is short from root apex, the tip of the file is observed beyond the cervical limit from AF. Resorption areas can be observed (SEM $10 \mathrm{kV}$ - 99). C: Endo-Eze Quill, precise in relation to the AF (SEM $10 \mathrm{kV}-77 \times$ ). 
There is no 100\% precision of EAL (4), and the possible differences among the results obtained with the different brands of EAL, can be related to the algorithm used in each one to calculate the quotient of the impedances of the frequencies measured. By another hand, it is important to know that AP and anatomic variations have an effect on EAL accuracy (25). The knowledge of anatomy and physiopathology of the periapical area and combined use of radiographic and electronic methods can improve the accurate determination of the WL in teeth with AP.

Root ZX II showed more precise than Endo-Eze Quill and Raypex 6 to locate the apical foramen in teeth with AP. The three EAL's tested showed a low level of precision considered the presence of AP.

\section{Resumo}

Os localizadores eletrônicos apicais têm sido usados para estabelecer o comprimento de trabalho no tratamento do canal radicular. Nos dentes diagnosticados com periodontite apical, a reabsorção das estruturas apicais dos dentes pode levar a dificuldades na obtenção de uma odontometria apropriada. Este estudo comparou três localizadores apicais (Root ZX II, Raypex 6 e Endo-Eze Quill) para localizar a ponta do instrumento K-file entre 0 a $-0,5 \mathrm{~mm}$ do forame apical em dentes com diagnóstico de periodontite apical assintomática. 0 comprimento de trabalho eletrônico foi realizado em 60 dentes com periodontite apical assintomática. Uma lima K-file de número 15 foi inserida no canal radicular até a localização do forame apical, e seguida foi reajustada para $-0,5 \mathrm{~mm}$ por meio de observação no visor do localizador eletrônico apical. A lima K-file foi fixada ao dente usando compósito, e a seguir os dentes foram extraidos. Os 4 milimetros apicais foram desgastados até que a lima K-file pudesse zer visualizada para as medidas de distância no forame apical por meio de microscópio eletrônico de varredura. 0 comprimento de trabalho apropriado foi determinado quando a ponta do instrumento estivesse localizada entre 0 a $-0,5 \mathrm{~mm}$ do forame apical. 0 Root ZX II apresentou o melhor desempenho $(p<0,01)$ que o Raypex 6 ou Endo-Eze Quill em dentes humanos com periodontite apical assintomática.

\section{Acknowledgements}

This research was funded partially by the Sub-Secretaria de Educación Superior, SEP, México, grant UDG-CA-657, IDCA 10087, Fortalecimiento de Cuerpos Académicos 2018. The authors deny any conflicts of interest related to this study.

\section{References}

1. Nair PNR, Sjögren U, Figdor D, Sundqvist G. Persistent periapical radiolucencies of root-filled human teeth, failed endodontics treatments and periapical scars. Oral Surg Oral Med Oral Pathol Oral Radiol Endod 1999;87:617-627.

2. Glossary of Terms Used in Endodontics. Chicago, IL: American Association of Endodontists, 2016.

3. Ricucci $D$, Langeland K. Apical limit of root canal instrumentation and obturation, part 2. A histological study. Int Endod J 1998;31:394-409.

4. Gordon MPJ, Chandler NP. Electronic apex locators. Int Endod J
2004;37:425-437.

5. Custer LE. Exact methods of locating the apical foramen. J Natl Dent Assoc 1918;5:815-819.

6. Suzuki K. Experimental study of iontophoresis. Japanese J Stomatol1942;16:411-429.

7. Sunada I. New method for measuring the length of the root canal. J Dent Res 1962;41:375-387.

8. Mc Donald NJ. The electronic determination of working length. Dental Clinics of North America 1992;36:293-297.

9. Delzangles B. Scanning electron microscopic study of apical and intraoral resorption. J Endod 1989;15:281-285.

10. Piasecki $L$, Carneiro E, Fariniuk LF, Westphalen VPD, Fiorentin MA, Silva Neto UX. Accuracy of Root ZX II in locating foramen in teeth with apical periodontitis: an in vivo study. J Endod 2011;37:1213-1216.

11. Vasconcelos BC, Araújo RBR, Alves e Silva FCF, Luna-Cruz SM, Duarte $\mathrm{MAH}$, Fernandes CAO. In vivo accuracy of two electronic foramen locators based on different operation systems. Braz Dent J 2014;25:1216.

12. Saatchi M, Aminozarbian MG, Hasheminia SM, Mortaheb A. Influence of apical periodontitis on the accuracy of 3 electronic root canal length measurement devices: an in vivo study. J Endod 2014;40:355-359.

13. ElAyouti A, Dima E, Ohmer J, Sperl K, Ohle C, Löst C. Consistency of apex locator function: A clinical study. J Endod 2009;35:179-181.

14. Wrbas KT, Ziegler AA, Altenburger MJ, Schirrmeister JF. In vivo comparison of working length determination with two electronic apex locators. Int Endod J 2007;40:133-138.

15. Stöber EK, Duran-Sindreu F, Mercadé M, Vera J, Bueno R, Roig M. An evaluation of Root ZX and iPex Apex locators: an in vivo study. J Endod 2011;37:608-610.

16. Duran-Sindreu F, Stöber EK, Mercadé M, Vera J, Garcia M, Bueno R et al. Comparison of in vivo and in vitro readings when testing the accuracy of the Root ZX apex locator. J Endod 2012;38:236-239.

17. Ravanshad S, Adl A, Anvar J. Effect of working length measurement by electronic apex locator or radiography on the adequacy of final working length. J Endod 2010;36:1753-1756.

18. Kuttler Y. Microscopic investigation of root apexes. J Am Dent Ass 1955;50:544-552.

19. Ricucci D. Apical limit of root canal instrumentation and obturation, part 1. Literature review. Int Endod J 1998;31:384-393.

20. Vier FV, Figueiredo JAP. Internal apical resorption and its correlation with the type of apical lesion. Int Endod J 2004;37:730-737.

21. Serry A, Adel M, Elden EM. Accuracy of electronic apex locator in relation to the condition of human dental pulp: histological and histochemical study. J Am Sci 2012;8:391-397.

22. Tsesis I, Blazer T, Ben-Izhack G, Taschieri S, Del Fabbro M, Corbella $S$ et al. The precision of electronic apex locators in working length determination: A systematic review and meta-analysis of the literature J Endod 2015;41:1818-1823.

23. Parente LA, Levin MD, Vivan RR, Bernandes RA, Duarte MAH, Vasconcelos BC. Efficacy of electronic foramen locators in controlling root canal working length during rotary instrumentation. Braz Dent J 2015;26:547-551.

24. Saatchi $M$, Aminozarbian MG, Noormohammadi H, Baghaei B. Influence of blood on the accuracy of raypex 5 and root ZX electronic foramen locators: an in vivo study. Braz Dent J 2016;27:336-339.

25. Piasecki L, Carneiro E, da Silva Neto UX, Westphalen VPD, Brandão $\mathrm{CG}$, Gambarini $\mathrm{G}$ et al. The use of micro-computed tomography to determine the accuracy of 2 electronic apex locators and anatomic variations affecting their precision. J Endod 2016;42:1263-1267.

Received March 16, 2019 Accepted July 23, 2019 